\title{
Correspondence
}

Letters to the Editor should not exceed 500 words.

\section{Trypanosomiasis in Britain}

SIR,-Two cases have recently come to my notice of failure to diagnose trypanosomiasis in an African in this country. In one, with the lapse of nearly three years since the patient was last in Africa, the possibility of a tropical cause of the illness may have been dismissed. In the other the presenting symptoms were personality changes, and trypanosomiasis was apparently never considered as a possible cause.

The chronic, Gambian form of trypanosomiasis may continue with virtually no symptoms for three, or even more, years before involvement of the central nervous system affects the patient noticeably. It may then present with complaint of persistent headache, with other meningeal symptoms, or with more apparently psychological signs such as increasing depression or with marked personality change, not infrequently with impaired responsibility.

I wish to make an urgent plea for the consideration of a diagnosis of trypano- somiasis in any person from Africa, whether African or not, now under medical care, perhaps even in a mental hospital, in this country with undiagnosed symptoms which could be due to trypanosomiasis. The finding of a C.S.F. protein of under $30 \mathrm{mg} . / 100 \mathrm{ml}$. and a normal cell count would be strong evidence against the diagnosis of trypanosomiasis, but if the C.S.F. protein is near or above $40 \mathrm{mg}$./ $100 \mathrm{ml}$., or if an abnormal cell count, particularly a lymphocytosis, in the C.S.F. is found, the possibility of trypanosomiasis should not be discarded until some other unquestionable cause has been found. If further opinion or advice is needed there are schools of tropical medicine with associated hospitals at London, Liverpool, and Edinburgh.-I am, etc.,

\section{K. C. Willett,}

Chairman International Scientific Council of Trypanosomiasis Research.

The London School of Hygiene and Tropical Medicine, London W.C.1.

\section{Serum Creatine Kinase and Exercise}

SIR,-In the paper of Drs. A. Vejiajiva and G. M. Teasdale (26 June, p. 1653) there are several points which merit discussion. The group of patients are all either " rugby players" or "oarsmen" and cannot be taken to be representative of the normal population. This is apparent (as the authors observe) in the fact that no less than one-quarter ( 3 out of 12) of the subjects exhibited pre-exercise serum-creatine-kinase (C.K.) values which are well outside the normal range for the method used.

One of the factors which makes serumC.K. estimations so useful is the consistency of values obtained in non-exercising but ambulant subjects. Using almost identical methods, the normal range has been shown to be remarkably constant by the estimations of Hughes in 73 subjects, ${ }^{1}$ Griffiths in 282 subjects," and by Pearce, Pennington, and Walton in 105 estimations in 87 subjects. $^{3}$ It is clear that the definite elevations (two to fourfold) of serum-C.K. activity in a quarter of the subjects reported by Drs. Vejiajiva and Teasdale are not representative of a random sample of healshy adults, and these high values implicate the operation of some other factor.

It is undoubtedly difficult to standardize physical exercise and to compare the results of one published series with another. Despite these inherent limitations, there has been a notable failure to demonstrate an increase in serum-C.K. levels after exercise in the studies reported. $^{3-5}$ A further point of importance is that the assumption that exercise does not alter serum-C.K. levels in patients suspected of having a myopathy does not appear to invalidate the value or the reliability of serum-C.K. estimations as a diagnostic measure. ${ }^{6-9}$ If exercise was even an occasional factor in the elevation of serum-C.K. levels, it would seem likely that a significant proportion of normal subjects and patients with neurogenic muscular atrophy would have an elevated C.K. value, which being recognized would pose a problem in the biochemical differentiation of such patients from those suffering from a primary myopathy. This has not arisen in the published reports.

All the subjects studied by Drs. Vejiajiva and Teasdale were of athletic inclination, and although the type and severity of the exercise performed for 80 minutes are not specified it seems reasonable to assume that the physiology of muscle contraction in the athlete may differ quantitatively from that of the more sedentary populace. Such subjects may have performed much more strenuou muscular exercise, and this could explain both the high pre-exercise C.K. levels and the increase which occurred after exercise. A good analogy is seen in patients suffering from tetanus, in whom moderate increases in serum-C.K. levels ocur ${ }^{10}{ }^{11}$; this is perhaps the best example of repeated muscular contraction of great severity.

It is therefore probable that only muscular exercise of considerable severity can increase the serum-C.K. activity. Such a degree of exertion is not common amongst members of the population carrying out their everyday tasks, and for this reason it is not necessary to impose a period of physical inactivity before taking blood for serum-C.K. estimation unless the patient has indulged in an unusual degree of exercise.-I am, etc.,

Department of Neurology, JoHN PeARCE. The General Infirmary, Leeds 1 .

\section{REFERENCES}

1 Hughes, B. P., Clin. chim. Acta, 1962, 7, 597. Griffiths, P. D., F. clin. Path., 1964, 17, 56. Pearce, J. M. S., Pennington, R. J., and Walton J. N.,

4 Hughes, B P in Research in Muscular Dystrophy, 2nd symposium, 1963, p. 167. Pitman,

Swaiman, K. F., and Awad, E. A., Neurology (Minneap.), 1964, 14, 977.

Dreyfus, J.-C., and Schapira, G., Klin. Wschr. 1962, 40, 373.

Richterich, R., Rosin, S., Aebi, U., and Rossi, E., Amer. F., hum. Genet., 1963, 15, 133 . Pearce, J. M. S., Pennington, R. J., and Walton, Pennington, R. J., and Walton, J. N., ibid., 1964, 27, 181

Mullan, D., and Dubowitz, V., Lancet, 1964,

${ }_{11}$ Pearce, J., unpublished data, 1965

SIR,-Drs. A. Vejjajiva and G. $M$ Teasdale (26 June, p. 1653) have given a timely reminder of the need for caution in interpretation of serum-creatine-kinase levels in view of the effect of prolonged physical exercise on the serum activity of this enzyme. ${ }^{2}$ The average serum-creatinekinase levels in a group of medical students taking part in the 1963 London to Brighton "stroll" increased sevenfold by the time they reached Gatwick (25 miles) and twentyfourfold by the end of the journey (53 miles). ${ }^{3}$ Prolongation rather than severity of muscular activity appears to be the important factor, as short-term severe exercise appears to be ineffectual. ${ }^{3-5}$ It is of interest perhaps that prolonged tachycardia also is associated with a marked increase in serum-creatine-kinase levels. ${ }^{6}$

The second important point is that some subjects may betray serum activities greater than the accepted upper limit of normal when carrying on their normal daily life-this occurs particularly in children and young adults, ${ }^{1-3}$ and is not necessarily related to the degree of physical labour involved. Such subjects might be termed "enzyme-labile"

Drs. Vejiajiva and Teasdale also point out that their normal range was based on a limited number of subjects. My studies based on 808 subjects forced me to adopt different normal ranges for adult ambulant and nonambulant subjects, as the upper limit of normal for the former was roughly twice that of non-ambulant subjects. For children, of course, only an ambulant range is necessary. Females tended to have a slightly lower range of serum-enzyme activities than did males.

These findings are of particular importance when creatine kinase is used for detection of biochemical carriers of the musculardystrophy gene, as the ranges for carriers and normal ambulant subjects overlap, ${ }^{6}$ and unless attention is paid to the circumstances under which the specimen is drawn an incorrect 
interpretation of the assay figure may ensue. - I am, etc.,

\section{P. D. Griffiths}

Bishop's Stortford, Herts.

\section{REFERENCES}

1 Aebi, u., Richterich, R., Colombo, J. P., and Rossi, E., Enzymol. biol. clin., 1961-2, 1, 61.
Lehmann, H., and Griffiths, P. D., Lancet, 1963, 2, 498.

Griffiths, P. D., 1964, M.D. Thesis. University of London. P., in Research in Muscular
Hughes, B. Dystrophy, Proceedings second symposium, p. 167, 1963. Pitman, London. Pearce, J'. M. S., Pennington, R. J., and Walton,
J. N., J. Neurol. Neurosurg. Psychiat., 1964, "Griffiths, P. D., in the press.

\section{Aortic Medionecrosis and the Marfan Trait}

SIR,-In Dr. M. G. Lewis's article (5 June, p. 1478) on the association between aortic medionecrosis and aortic incompetence in the elderly he also mentions that some of these cases show evidence of arachnodactyly, suggesting the presence of an underlying congenital connective-tissue defect. The classical Marfan syndrome of arachnodactyly, aortic dilatation, and congenital eye defects is fairly easily recognized in young adults, but patients have now been described in whom the cardiovascular changes have presented in the sixth decade. $^{12}$ In these cases the Marfan trait must be less severely expressed, as the abnormal aorta is able to withstand the haemodynamic thrust of the circulation for a longer period before starting to dilate.

For several years I have been searching for patients with the characteristics of the skeletal disorder of dolichostenomelia (long slender limbs), ${ }^{3}$ originally described by Marfan." Viewed from this aspect, vascular and eye defects are uncommon, although the arachnodactyly may be as severe as that seen in patients with these complications. However, one of my patients was found to have aortic regurgitation and radiological evidence of dilatation of the first part of the aorta at the age of 61 years.

Sinclair et al..$^{5}$ devised the metacarpal index from bone measurements of radiographs of the hands. I regard measurements above the $3 \times$ Standard Deviation (S.D.) of the normal range of this index as being indicative of arachnodactyly. ${ }^{6}$ It is beyond this amount of bone slenderness (occurring in about 1 in 400 persons) that I began to find patients with an aorta which has dilated. Unfortunately the metacarpal index does not always detect the minor degrees of arachnodactyly, which one might expect in the older patients presenting with a vascular abiotrophy. Consequently I devised a method of estimating the relative slenderness of all the metacarpals and proximal phalanges. ${ }^{3}$ I now present this information on skeletal hand charts, in which the abnormal measurements are clearly indicated as multiples of the normal standard deviation. This has produced the interesting finding that the Marfan trait is expressed extremely irregularly even in one region such as the hands and may even be confined to one hand. In McKusick's case ${ }^{2}$ the cardiovascular defect was also expressed irregularly, so that the aortic valve and descending thoracic aorta had dilated and yet the ascending aorta had withstood a greater haemodynamic thrust. Idiopathic Erdheim's cystic medionecrosis without the Marfan trait is a diagnosis of exclusion, and skeletal hand charts may help to determine the presence of a connective-tissue defect before it is too late.

Now that it is possible to splint the aorta with a sleeve of synthetic material or replace a segment with a synthetic graft-a lifesaving procedure in one of my patients-the diagnosis of this condition has become increasingly important.-I am, etc.,

$$
\begin{gathered}
\text { Passmore Edwards Medical J. G. PARISH. } \\
\text { Rehabilitation Centre, } \\
\text { Clacton-on-Sea, Essex. } \\
\text { REFERENCES }
\end{gathered}
$$

\section{Experience in an Anti-smoking Clinic}

SIR,-Dr. Keith P. Ball and his team (26 June, p. 1651) are to be congratulated on their splendid work at their anti-smoking clinic. The group therapy idea which forms the basis of several such clinics in this country has certainly muth to be recommended from the very sound reasons stated in the report. While I don't think that any method employed in the treatment of smokers who really want to give up smoking can claim better results than those shown by Dr. Ball and his colleagues, I succeeded quite as well with the personal clinical approach. In January 1963 I inaugurated with the support of the Ministry of Health a "Smokers' Advisory Clinic" as a new service of the corporation's health and social services department in one of Newcastle's public health clinics. During the first year this new enterprise had been run as an experimental clinic with the special approval of the Ministry. After an interval of several months we reopened the clinic nine months ago. Since then 78 peoplemostly referred by their doctors, unless they came from reasons of their own-attended the clinic. Though the corporation charges a fee of $35 \mathrm{~s}$. per patient in order to cover the expenses (overheads and drugs)-a payment also designed to deter those timewasters who are not really serious about this business-15 customers (c. 20\%) dropped out after the first or second session. Of the remaining 63 patients-among them many bronchitics-four are not yet " consolidated." Of the 59 under assessment 16 $(27 \%)$ did not respond or gave up treatment prematurely; $43(72 \%)$ gave up smoking, usually the same day as strongly suggested. The almost immediate results with a few exceptions who needed a week or so was, I believe, only possible by supplying the strong moral support and psychological influence (i.e., by demolishing the myth of the benefit of smoking and by dealing carefully with the patient's individual problems) with effective drug treatment. I used either lobeline (no less than 12-16 mg. per day) in order to prevent the craving, or Atarax (hydroxyzine) in individually required doses (10 mg. two to four times per day) for the suppression of " deprivation symptoms." The patient has to be warned against a possible somniferous effect of hydroxyzine during the first two days.

Following up is notoriously difficult, as many people don't return the short follow-up questionary. So far we could trace nine relapses; three of these want to repeat the course of treatment. Of those who replied, 10 are still abstinent for periods from three to eight months.-I am, etc., E. G. W. Hoffstaedt.

Newcastle upon Tyne.

\section{Buphthalmos and Photophobia}

SIR,-In the section on buphthalmos in Mr. K. Wybar's interesting article on eye diseases in children in the B.M.F. of 22 May (p. 1361) he gives increasing myopia in early childhood, haziness of the cornea, redness of the eye, and photophobia as presenting signs, in that order. I entirely agree with him that these conditions occur, but would give a different order of, as it were, priority, and add lacrimation.

Increasing myopia would be unlikely to become manifest until the child is at least 2 or 3 years old, whereas Iacrimation and photophobia present themselves in the first months or year of life, and this is the time when it is most important for the case to be observed and treated. Furthermore, it is remarkable how often these two symptoms are not given the consideration they deserve. The lacrimation is ascribed to blocked tear ducts and the photophobia is thought to be something out of which the child will grow; so that it is sometimes months or even longer before it is realized that there is something seriously wrong.

Congenital glaucoma is treatable, and satisfactorily so if it is " caught" in the first year of life, after which the prognosis becomes progressively worse. The reason for this letter, therefore, is to draw the attention of all who have to do with young children to the possibly sinister significance of photophobia and lacrimation, especially the former.-I am, etc.,

London $\mathrm{W} .1$.

Arthur Lister.

\section{Death after Combined Dexamphetamine and Phenelzine}

SIR,-Episodes of hypertension may occur during treatment with monoamine-oxidase inhibitors, and are sometimes related to the simultaneous administration of other drugs -e.g., amphetamine-or to eating cheese The following is an account of a case in which dexamphetamine was taken during a course of treatment with phenelzine, resulting in a rise of blood-pressure, cerebral haemorrhage, and death.

A 30-year-old woman with depression was being treated with phenelzine (Nardil) $15 \mathrm{mg}$. three times daily, and trifluoperazine (Stelazine) $2 \mathrm{mg}$. at night. One afternoon, after she had been taking these drugs for some five weeks, she acquired some dexamphetamine tablets (Dexten) from a friend, and took two (each equivalent to $10 \mathrm{mg}$. dexamphetamine sulphate) Within a quarter of an hour she was complaining of a headache, so severe that she called her doctor and told him "her head was bursting." Her blood-pressure when taken an hour after the ingestion of the dexamphetamine was $150 / 100$ $\mathrm{mm}$. $\mathrm{Hg}$, but at this time there were no physical 